Abstract PS4:68 Table 3 Relative risk conferred by ASP-related factors for increased number of subclinical atherosclerotic plaques in the carotid and ferroral arteries, corresponding 95\% confidence intervals (CI), and p-values for interaction between each APS-related factor and APS type

\begin{tabular}{|c|c|c|c|}
\hline APS-related factor** & $\begin{array}{l}\text { PHPS } \\
\text { RR(95\%CI) }\end{array}$ & $\begin{array}{l}\text { SLEIAPS } \\
\text { RR }(95 \% \mathrm{CI})\end{array}$ & $\begin{array}{l}\text { P-value for } \\
\text { difference } \\
\text { between PAPS } \\
\text { and SLE/APS }\end{array}$ \\
\hline Previous artenal thoonbosis & $2.10(0.85-5.31)$ & $1.66(0.67-4.11)$ & 0.716 \\
\hline Ant-cardiolypun IgG positivity & ए.72(ए.17-1.73) & $1.35(0.45-2437)$ & 0.343 \\
\hline Ant-cardiolipan lgM positinty & ए.95(0.43-2.06) & $0.86(0.37-8.24)$ & ए.859 \\
\hline Ant- इ2GPIIGG positivty & ए.81(0.41-1.60) & $4.43(1.7-11.10)$ & ए.0us \\
\hline Ant-52/52GPIgM positinty & U.79(0.39-1.64) & $1.13(0.45-1451)$ & 0.553 \\
\hline Lupus Arthcosgulant positinty & $0.87(0.42-1.78)$ & $1.15(0.45-2.95)$ & 0.631 \\
\hline $\begin{array}{l}\text { Tnple antiphospholped } \\
\text { antib ody positivity }\end{array}$ & 0.81(0.38-1.71) & $1.53(0.67-3.52)$ & U.296 \\
\hline $\begin{array}{l}\text { High Antphospholipd } \\
\text { antib ody titers } \S\end{array}$ & U.91(ए.46-1.83) & $4.03(1.63-9.97)$ & U.ण16 \\
\hline
\end{tabular}

term of interactionbetween the factorin question and APS type age, gender hypertersion, dyslipidemia pack years of s molking, farrily his tory of connary artery disease, and body mass index 5 Greater than four-fold of the upper nomal limit in any antiphospholipid antbody

PAFS : Primary Antiphospholipid Syndrome; SLEJAFS : Systervic Lupus Erythematosus-as ociated Antiphospholipid Syndrome

\section{PS4:69 EPIDEMIOLOGY OF VASCULAR PRIMARY ANTIPHOSPHOLIPID ANTIBODIES SYNDROME}

${ }^{1} \mathrm{C}$ Nalli, ${ }^{1} \mathrm{G}$ Pascariello, ${ }^{1} \mathrm{~A}$ Zentilin, ${ }^{2} \mathrm{E}$ Raffetti, ${ }^{1} \mathrm{~L}$ Andreoli, ${ }^{3} \mathrm{C}$ Gasparotti, ${ }^{3} \mathrm{M}$ Magoni, ${ }^{3} \mathrm{C}$ Scarcella, ${ }^{2} \mathrm{~F}$ Donato, ${ }^{1} \mathrm{~A}$ Tincani. ${ }^{1}$ U.O. Reumatologia e Immunologia Clinica, Asst Spedali Civili, Brescia, Italy; ${ }^{2}$ U. O. Igiene e Sanita' Pubblica, Asst Spedali Civili, Brescia, Italy; ${ }^{3}$ Agenzia di Tutela della Salute di Brescia/Brescia Health Protection Agency, Brescia, Italy

\subsection{6/lupus-2018-abstract.115}

Objective Antiphospholipid Syndrome(APS)is a systemic autoimmune disease characterised by the presence of thrombotic and/or obstetrical manifestations and antiphospholipid antibodies (aPL). In 2006 were published the Sapporo criteria for APS but by now no epidemiological study on this disease were performed. Incidence and prevalence of primary APS (PAPS) are still unknown. The aim of this study was to evaluate the prevalence during the year 2013 and incidence for the period 2011-2015 of vascular PAPS in the adult population of a defined area, Valtrompia valley,using multiple sources. Valtrompia is a 40 kilometers-long prealpine valley in northern Italy. The population in 2013 was 101.477 inhabitants. The only easy access to the valley is from Brescia, the main city of the province. This valley is a cul-de-sac area without any other comfortable and practicable access. Therefore,this valley is ideal for epidemiological studies. In addition, the only Rheumatology referral tertiary Centre of the province is located in Brescia. This project was approved by the local Ethical Committee.

Methods We identified adult subjects of 18-50 years old living in Valtrompia. Patients with thrombotic events were identified by two sources:

- hospital demission code using key words (deep vein thrombosis, pulmonary embolism, myocardial infarction, ischaemic stroke);

- patients with defined diagnosis of vascular PAPS already followed by the Rheumatology tertiary Centre in Brescia.

Results We identified 47 patients with venous events during 2011-2015. 27/47 (57\%) were tested for aPL, 4/27 (15\%) positive. Regarding arterial events, 36 patients had stroke and $33 / 36$ (92\%) were tested for aPL, 4/33 (12\%) positive. Finally, 64 patients with myocardial infarction (IMA): only 14/64 (22\%) were tested for aPL, 2/14 (14\%) positive. Table 1 shows incidence of vascular PAPS. Prevalence was 35.4 (95\% CI: 20.6 to 59.6) per 100.000 inhabitants in 2013.

Conclusions Preliminary results of this study showed that PAPS is a rare disease and accurate epidemiological studies are necessary to better characterised patients. Another point is that aPL were not routinely tested in young subjects with vascular events, especially in patients with myocardial infarction.

Results will be updated, we are going to recall patients never tested for aPL during the hospital admission. 
Abstract PS4:69 Table 1 Incidence rates of antiphospholipid antibody syndrome per 100.000 inhabitants in valtrompia in adult population (18-49 year) between 2011 and 2015. The 95\% confidence intervals (Cls) are reported in parenthesis

\begin{tabular}{|c|c|c|}
\hline & \multicolumn{2}{|c|}{ INCIDENCE } \\
\hline & Number of cases & $\begin{array}{c}\text { Incidence (95\% CI) } \\
\text { per } \mathbf{1 0 0 , 0 0 0}\end{array}$ \\
\hline OVERALL & & $3.7(1.7-7.1)$ \\
\hline Males + Females & 9 & $4.0(1.3-9.4)$ \\
\hline Males & 5 & $3.4(0.9-8.8)$ \\
\hline Females & 4 & \\
\hline VENOUS THROMBOSIS & & $1.7(0.5-4.3)$ \\
\hline Males + Females & 4 & $0.8(0.0-4.5)$ \\
\hline Males & 1 & $2.6(0.5-7.5)$ \\
\hline Females & 3 & $1.7(0.5-4.3)$ \\
\hline STROKE/ICTUS & & $2.4(0.5-7.1)$ \\
\hline Males + Females & & $0.9(0.0-4.8)$ \\
\hline Males & 4 & \\
\hline Females & 3 & $0.4(0.0-2.3)$ \\
\hline & 1 & $0.8(0.0-4.5)$ \\
\hline IMA & & - \\
\hline Males + Females & 1 & \\
\hline Males & 1 & \\
\hline Females & 0 & \\
\hline
\end{tabular}

\section{PS4:70 ANTI-PHOSPHATIDYLSERINE/PROTHROMBIN ANTIBODIES AND CARDIOVASCULAR RISK IN A SLE COHORT OF PATIENTS}

${ }^{1} \mathrm{~V}$ Canti, ${ }^{1,2} \mathrm{GA}$ Ramirez, ${ }^{1} \mathrm{E}$ Bozzolo, ${ }^{1} \mathrm{~S}$ del Rosso, ${ }^{2} \mathrm{R}$ Erra, ${ }^{1,2} \mathrm{~A}$ Manfredi, ${ }^{1,2} \mathrm{P}$ RovereQuerini. 'Ospedale San Raffaele, Milan, Italy; ${ }^{2}$ Università Vita-Salute San Raffaele, Milan, Italy

\subsection{6/lupus-2018-abstract.116}

Introduction Clinical activity of SLE may wax and wane, but persistent, active systemic inflammation leads to organ damage and rises morbidity and mortality. Early damage is mostly related to disease activity, whereas later damage, in particular atherosclerosis, infections and malignancies are usual complications of long-standing disease and treatment with immunosuppressive agents. One of the major late causes of death in SLE is thrombosis, in particular stroke and myocardial infarction due to CAD. In these patients, the increased cardiovascular morbidity is not fully explained by traditional risk factors and this may lead to under-recognition and under-treatment. Petri, et al. proposed an equation for cardiovascular disease risk in SLE, which combines classical parameters and disease activity markers. Other scores such as the GAPSS(Global AntiPhospholipid Syndrome Score) have been recently evaluated. The importance of aPL in thrombosis in general is well defined, as they constitute the culprit of the so-called anti-phospholipid
syndrome(APS). Their role in sustaining the high risk of cardiovascular complications of SLE patients is under-debated.

Objective To study the role of the anti-phosphatidylserine/prothrombin(aPS/PT) antibodies, included in the GAPSS score, in contributing to the thrombotic risk of SLE patients.

Methods We enrolled 172 patients from Ospedale San Raffaele. 132 patients with SLE(111/132, 84\% without secondary APS, SAPS, and $21 / 132,16 \%$ with SAPS), 19 with primary APS(PAPS) and 21 healthy controls. Each recruited patient was tested for aPS/PT IgG and IgM through ELISA by INOVA Diagnostic, Inc. San Diego, CA USA.

Results 36/111 (32.4\%) SLE without APS, 15/21 (71.4\%) SAPS, $13 / 19(68.4 \%)$ PAPS and 3/21 (14.3\%) healthy donors were aPS/ $\mathrm{PT}+$. aPS/PT+SLE patients had a higher cardiovascular risk according to the Petri's score, when compared to aPS/PT-patients, irrespectively of a positive or negative history of overt APS (Mean \pm SD Petri' score $=20.8 \pm 18.1,14.0 \pm 12.8$ and 23.8 \pm 22.5 , $11.6 \pm 9.3$ respectively, $\mathrm{p}<0.05)$. Accordingly, the GAPSS score was significantly higher in APS patients than in APS negative patients with SLE(12.1 $\pm 5.7,11.5 \pm 4.6$ and $4.9 \pm 4.9$ respectively, $\mathrm{p}<0.001)$. Patients with a GAPSS score $>10$ had also higher prevalence of pregnancy complications.

Conclusion aPS/PT antibodies are associated with a high risk of thrombosis and CAD in SLE. aPS/PT assays should be routinely introduced in the management of these patients. 